\title{
A study of magnitude of anemia and its association with diet pattern in young females
}

\author{
Neelakandan Ramya ${ }^{1}$, Sethu Prabhu Shankar ${ }^{2}$, Janarthanan Arvind ${ }^{3 *}$ \\ ${ }^{1,2}$ Professor, ${ }^{3}$ Post Graduate, Dept. of General Medicine, Aarupadai Veedu Medical College and Hospital, Pondicherry, India
}

*Corresponding Author: Janarthanan Arvind

Email: arvinda420@gmail.com

\begin{abstract}
Background: Due to lack of consumption of nutrients by cell the Nutritional anemia occurs. Iron, folic acid, Vitamin B12, Vitamin B6, Vitamin $\mathrm{C}$ and protein are vital nutrients whose deficiency can lead to nutritional anemia.

Aim: To study the magnitude of anaemia in young females and its association with diet pattern.

Materials and Methods: Study was done as a cross-sectional study in young females of age 18 to 40 . Demographic details like age, height, body weight, and the dietary patterns comprising food habits were recorded. Hematological parameters were obtained using automated haematology cell counter and peripheral blood smears by microscopy.

Results: In this study 100 females were included, $62 \%$ of participants were anemic, the mean years of age in the study participants was $26.52 \pm 3.48$ years. $44 \%$ of participants had mild anemia followed by $16 \%$ had moderate anemia and $2 \%$ had severe anemia. On further analysis of dietary habits, $47 \%$ of women not taking green leafy vegetables had mild to moderate anemia, $25 \%$ of women drinking tea or coffee after the meal had mild anemia and $14 \%$ of women eating junk foods and $5 \%$ of women eating less fruits had mild to moderate anemia.

Conclusion: Improving women's health education on the consumption of iron-rich foods and healthy diet habits is instrumental in preventing nutritional anemia could be the single most important intervention to reduce India's anemia burden.
\end{abstract}

Keywords: Anemia, Diet, Green leafy vegetables.

\section{Introduction}

Appropriate nutrition is essential to deliver this vital element and other micronutrients to lessen the risk of anemia. World Health Organisation is determined to decrease anemia universally by $50 \%$ till $2025 .^{1}$ The gender discrimination from their birth in our society even in this modern days leads to the low health status of young girls in our country. Discriminatory delivery of health resources inside households and society is the important basis of nutritional anemia among the females. ${ }^{2}$ According to WHO most common cause of anemia is iron-deficiency anemia.

Nutritional anemias may result from various vitamin and mineral, as well as some macronutrient deficiencies, but the most common are megaloblastic anemia, resulting from folic acid or vitamin B12 deficiency, and microcytic, hypochromic anemia, resulting from iron deficiency.

Among the micronutrients, Iron is very essential for cellular growth, immune function, enzymatic reaction, oxygen binding, transport and storage, mental growth and physical growth. Dietary iron is available in two forms: heme iron, which is found in meat and nonheme iron, which is found in plant and dairy foods. Iron absorption takes place in the duodenum and some part of the jejunum. Maximum of total body iron is found flowing in heme, commonly in erythrocyte hemoglobin $(\mathrm{Hb})$, the residual one third is deposited in tissues and other cells as ferritin and hemosiderin. ${ }^{3}$

Iron deficiency (ID) is a state in which there is inadequate iron to preserve the normal physiological function of tissues. ${ }^{4}$ Nutritional cause of iron deficiency is the intake of cereal-based diets, which provide non-haem iron of poor bioavailability ${ }^{3}$, extended negative disproportion between a person's dietary intake of iron and their body's physiological demand $^{5,6}$ and non-nutritional causes of anemia includes malaria, hemodialysis patients, hookworm infestation, chronic infection and inflammation, and hemoglobinopathies such as thalassemia. ${ }^{7-11}$

Iron deficiency anemia is the commonest nutritional disorder found all over the world, predominantly in the developing countries, mostly, affecting young children of 624 months of age, adolescents, women of reproductive age group and pregnant/ lactating women. ${ }^{12,13}$ Although iron deficiency affects all age group and both the sexes adolescent females are more predisposed to it. The cause for iron deficiency in females is reduced intake or delay in absorption, increased demand during adolescence, heavy blood loss during menstruation and parasitic infection. Iron deficiency during pregnancy is related with maternal mortality, preterm labor, low birth-weight, and infant mortality. ${ }^{3}$

From the 2005-2006 National Family Health Survey (NFHS) data, the prevalence of anemic females in the age group between 18-49years was 55\%. ${ }^{14}$ Globally in 2011, among the pregnant women the prevalence of anemia was about 38\% (32.4 million pregnant women), and non-pregnant women is about $29 \%$ (496.3 million non-pregnant women), and for all women in the reproductive age group is about $29 \%$ (528.7 million women of reproductive age). ${ }^{15}$ Here in our study, we have studied the magnitude of iron deficiency anemia in young females and its association with diet pattern.

\section{Aim}

To study the magnitude of anaemia in young females and its association with diet pattern.

\section{Materials and Methods}

\section{Study design and setting}

It was a hospital based cross-sectional study conducted in the department of General Medicine, Aarupadai Veedu Medical College and Hospital, Pondicherry. 


\section{Sample size and sampling}

Based on the case load and feasibility the sample size was 100 and All the female patients between age group18-40 years willing to give informed consent were included in this study. The exclusion criteria were patients with chronic systemic illness, on iron or any multivitamins, history of menorrhagia and pregnancy.

\section{Data collection}

After obtaining the informed oral and written consent in their native language. Demographic details like age, height, body weight and the dietary patterns comprising food habits were recorded. Hematological parameters were obtained using automated haematology cell counter and peripheral blood smears by microscopy ${ }^{22}$ As per the WHO criteria the severity of anemia was categorized. According to the WHO criteria Hemoglobin levels below $12.0 \mathrm{gm} / \mathrm{dl}$ were considered anemia. Hemoglobin levels of 10.0-11.9 gm/dl are graded as mild anemia, hemoglobin $7-9.9 \mathrm{gm} / \mathrm{dl}$ and,$<7 \mathrm{gm} / \mathrm{dl}$ is graded as moderate and severe anemia respectively.

\section{Data analysis}

Data entry was done and descriptive analysed was done in terms of Mean \pm SD for continuous variables, and frequencies and percentages using MS excel.

\section{Results}

In this study 100 females between 18 to 40 years were included, the mean age of these participants was $26.52 \pm 3.48$ years. Majority of study participant was in 18 to 30 years (72\%) and $28 \%$ in more than 31 years. $61 \%$ of study participants are following non-vegetarian diet and 39\% of participants are following the vegetarian diet. (Fig. 1 and 2)

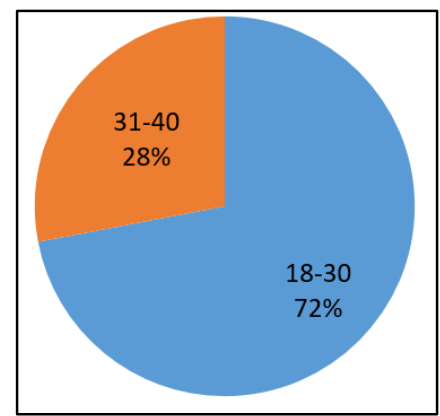

Fig. 1: Distribution of age group

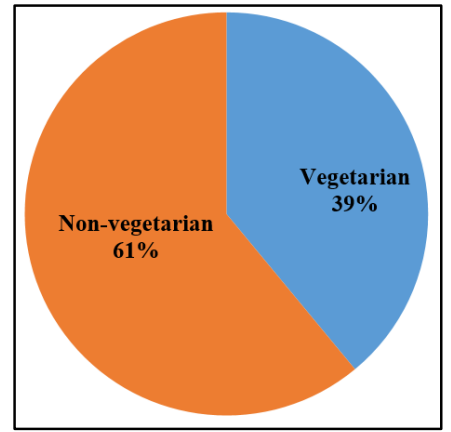

Fig. 2: Distribution of the diet
Table 1: Distribution of anthropometric and hematological variables

\begin{tabular}{|l|c|c|}
\hline Variables & Mean & SD \\
\hline Age & 26.52 & 3.48 \\
\hline Height in cm's & 156.72 & 6.50 \\
\hline Weight in kg & 58.92 & 8.72 \\
\hline Body mass index (BMI) & 22.52 & 2.67 \\
\hline Hemoglobin in g/dl & 10.06 & 1.87 \\
\hline Mean corpuscular volume (MCV) & 78.58 & 13.12 \\
\hline $\begin{array}{l}\text { Mean corpuscular hemoglobin } \\
\text { (MCH) }\end{array}$ & 26.00 & 4.50 \\
\hline $\begin{array}{l}\text { Mean corpuscular hemoglobin } \\
\text { concentration (MCHC) }\end{array}$ & 32.50 & 2.89 \\
\hline
\end{tabular}

The mean BMI of the study participant was $22.52 \pm 2.67$, with mean height of $156.72 \mathrm{cms}$ and weight of $58.92 \mathrm{kgs}$. The mean hemoglobin level of the study participants was $10.06 \pm 1.87 \mathrm{gm} / \mathrm{dl}$. The mean value of $\mathrm{MCV}$ in study participants was $78.58 \pm 13.12 \mathrm{fl}$, mean $\mathrm{MCH}$ was $26 \pm 4.50 \mathrm{pg}$ and mean MCHC was $32.50 \pm 2.89 \mathrm{gm} / \mathrm{dl}$. (Table 1)

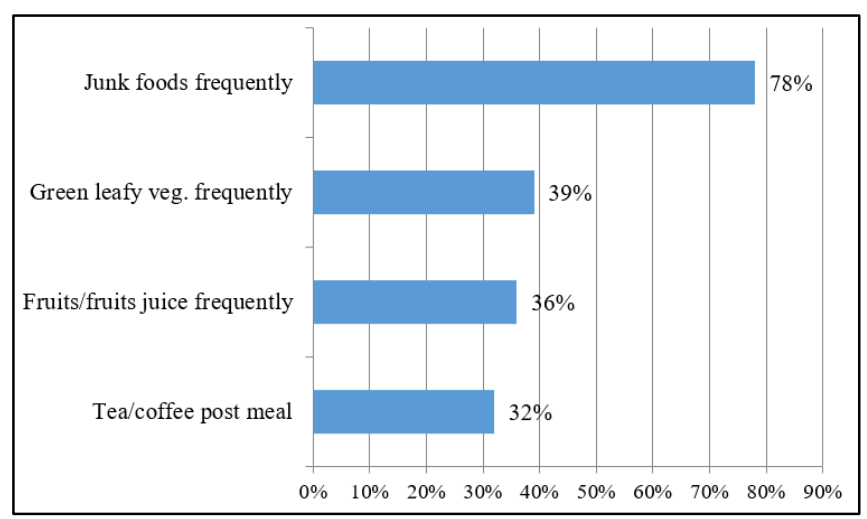

Fig. 3: Depicting the dietary habits among participants

In this study, $78 \%$ of participants were taking junk foods frequently, $32 \%$ of participants were taking tea or coffee after a mean, $36 \%$ and $39 \%$ of participants are taking fruits and green leafy veg. respectively. (Fig. 3)

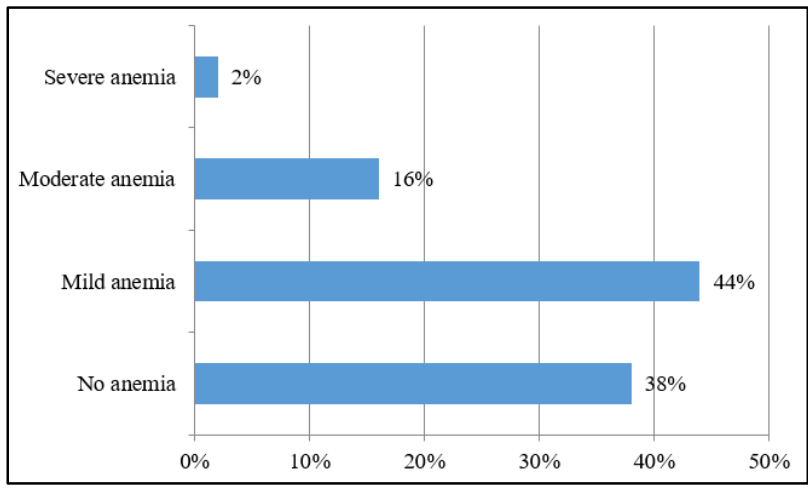

Fig. 4: Describing the severity of anemia

In this study, the incidence of anemia is $62 \%, 44 \%$ of participants had mild anemia followed by $16 \%$ had moderate anemia and $2 \%$ had severe anemia. 


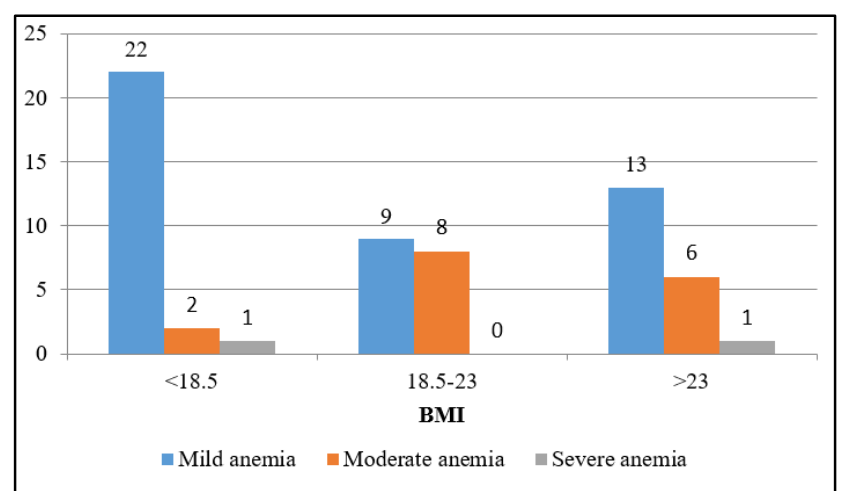

Fig. 5: Distribution of anemia with weight

On further analysis weight, it was observed that $55 \%$ of underweight, $56 \%$ of normal weight and $80 \%$ of overweight participants were anemic (Fig. 5)

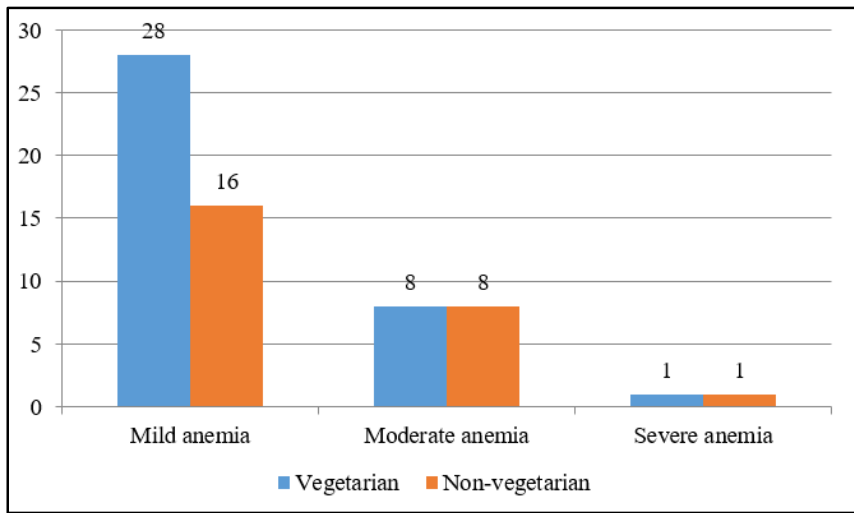

Fig. 6: Distribution of anemia with diet

On further analysis of diet patterns, it was observed that $94 \%$ of vegetarian and $40 \%$ of non-vegetarian participants were anemic. (Fig. 6)

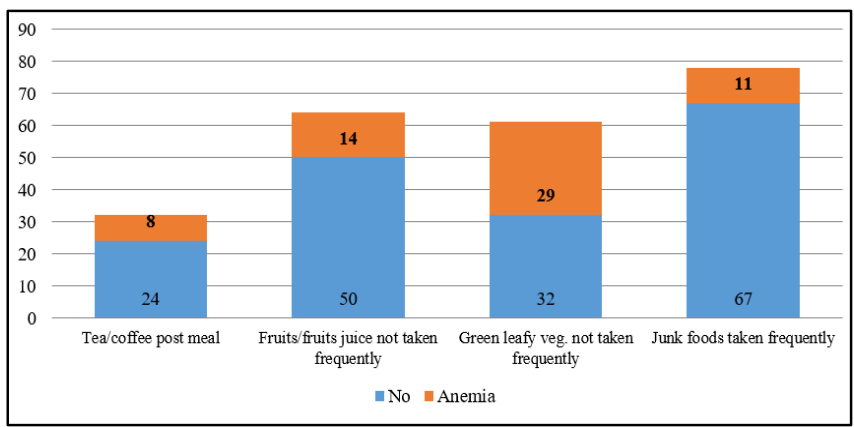

Fig. 7: Distribution of anemia with food habits

On further analysis food habits, it was observed that $47 \%$ of women not taking green leafy vegetables had mild to moderate anemia, $25 \%$ of women drinking tea or coffee after the meal had mild anemia, $14 \%$ of junk foods eaters and 5\% of fruits eaters had mild to moderate anemia. $2 \%$ of women in severe anemia did not take green leafy vegetables in their diet in a week in their diet menu (Fig. 7).

\section{Discussion}

There is an alarming high prevalence of iron deficiency anemia among the young females is due to the concerns on health and productivity. Iron acts as the crucial factor in erythropoiesis. Prolonged negative iron balance due to the inadequate intake of iron in their diet or its poor bioavailability, augmented necessities for iron all through their growth and pregnancy. During the menstruation and also during the worm infestations there is an increased iron losses. ${ }^{15}$

In this study, the prevalence was $34 \%$ in the age group 18 to 45 years. Aggarwal et al. in their study conducted among adolescent girls in the North East Delhi showed 45\% prevalence of anemia. ${ }^{16}$ In the District Level Health Survey (DLHS 2002-04), this survey was done about 18 years ago so there difference in the prevalence in our study is due to the lifestyle, urbanization, food pattern, and food taboos. From the same survey DLHS its showed that a higher prevalence of severe anemia $(21.1 \%)$ which matches with our study (17.6\%). In India, Bihar has the highest prevalence of anemia according to the National statistic which is $87.6 \% .^{18}$

Similar to our study the prevalence of mild and moderate anemia was more in the Kaur IP and Kaur S et al study. In our study on comparing the diet pattern, anemia seems to be more common among those who prefer vegetarian foods. Kaur IP and Kaur S observed that almost $98 \%$ of the Punjabi girls were anemic, maximum number of girls were in moderate category of anemia. ${ }^{18}$ Dixit et al did a study on 596 adolescent girls of Lucknow and he found that $83.3 \%$ of anemia prevalence and which is interestingly matches with our study outcome. ${ }^{20}$

In Maharashtra, Panat el al did a study in Ahmed Nagar, with 273 girls and they found that maximum number of girls has mild anemia and it was found that anemia was significantly common among the girls who followed the habit of having tea in their post meal, which is comparable to our study. ${ }^{21}$ Panat et al recoded a very weak positive correlation between hemoglobin and the normal Body Mass Index. Also they showed a very weak negative correlation among the low, high BMI and hemoglobin which in statistically insignificant. In the present study anemia was identified even in the girls who had normal BMI. In the current study, $47 \%$ of women not taking green leaf vegetables had mild to moderate anemia, 25\% of women drinking tea or coffee after the meal had mild anemia, $14 \%$ of junk foods eaters and $5 \%$ of less fruits eaters had mild to moderate anemia. $2 \%$ of women in severe anemia did not take green leaf vegetables, fruits in their diet.

Regarding the young girls it is understood that anemia is the major health concern due to their poor diet pattern which not much included with green leafy vegetables and fruits. Rather they prefer for more junk foods and lack of awareness of nutrition and their health.

The limitations of the study were the participants were purposive sampling and the study conducted in small small size and with limited resource. Though this study didn't bring explore more, but the outcome of the study have added the value to the already existing literature. 


\section{Conclusion}

Iron deficiency anemia is common in young females. Iron deficiency anemia is appreciated in young females with poor dietary habits. Health education among young females with regards to healthy diet habits is instrumental in preventing nutritional anemia.

\section{Source of Funding}

None.

\section{Conflict of Interest}

None.

\section{References}

1. Global Nutrition Targets 2025: Anaemia policy brief [Internet]. World Health Organization. 2014 [cited 6 March 2020]. Available from: https://www.who.int/nutrition/publications/globaltargets2025_ policybrief_anaemia/en/

2. Shanti D, Vidya D, Ramesh V. Prevalence of anemia among adolescent girls: A school based study. Int J Basic App Med Res. 2015;5:95-8.

3. Zimmermann MB, Hurrell RF. Nutritional iron deficiency. Lancet. 2007;370(9586):511-20.

4. Benoist BD, McLean E, Egll I, Cogswell M (2008): Worldwide prevalence of anemia 1993-2005: WHO global database on anemia. Worldwide prevalence of anemia 19932005: WHO global database on anemia. https:// www. cabdirect. org/ cabdirect/abstract/20093013528.

5. Abbas PN, Hurrell R, Kelishadi R. Review on iron and its importance for human health. J Res Med Sci (J Isfahan Univ Med Sci). 2014;19(2):164.

6. Hurrell R, Egli I. Iron bioavailability and dietary reference values-. Am J Clin Nutr. 2010;91(5):1461S-7S.

7. Ahmed F, Al-Sumaie MA. Risk factors associated with anemia and iron deficiency among Kuwaiti pregnant women. Int $J$ Food Sci Nutr. 2011;62(6):585-92.

8. Stoltzfus RJ, Albonico M, Chwaya HM, Savioli L, Tielsch J, Schulze K, et al. Hem quant determination of hookwormrelated blood loss and its role in iron deficiency in African children. Am J Trop Med Hyg. 1996;55(4):399-404.

9. Madore F. Anemia in hemodialysis patients: variables affecting this outcome predictor. J Am Soc Nephrol. 1997;8(12):1921-9.

10. Dreyfuss ML, Stoltzfus RJ, Shrestha JB, Pradhan EK, LeClerq SC, Khatry SK, et al. West Jr KP (2000): Hookworms, malaria and vitamin A deficiency contribute to anemia and iron deficiency among pregnant women in the plains of Nepal. $J$

Nutr. 130(10):2527-36.

11. Semba RD, Bloem MW. The anemia of vitamin A deficiency: epidemiology and pathogenesis. Eur J Clin Nutr. 2002;56(4):271.

12. Lokeshwar MR, Mehta M, Mehta N, Shelke P, Babar N. Prevention of iron deficiency anemia (IDA): How far have we reached? Indian J Pediatr. 2011;78(5):593-602.

13. Abu-Ouf NM, Jan MM. The impact of maternal iron deficiency and iron deficiency anemia on child's health. Saudi Med J. 2015;36(2):146.

14. Arnold FS. Parasuraman, P. Arokiasamy, and M. Kothari, "Nutrition in India," in National Family Health Survey (NFHS-3) India 2005-06.

15. World Health Organization. The global prevalence of anaemia in 2011. Geneva: World Health Organization; 2015. [21 May 2019].

16. Shill KB, Karmakar P, Kibria MG, Das A, Rahman MA, Hossain MS, et al. Prevalence of iron-deficiency anemia among university students in Noakhali region, Bangladesh. $J$ Health Popul Nutr. 2014;32:103-10.

17. Aggarwal KN. Assessment of prevalence of anemia and iron stores in response to daily/weekly iron folate supplements in adolescent girls(10-18) from urban slums of East Delhi. UNICEF Contract No. 95/0075. 1998:i-9.

18. Park K. Textbook of Preventive and social medicine, 24th ed. Jabalpur, M/s Bansidas bhanot publisher;2016:646-704.

19. Kaur IP, Kaur S. A comparison of nutritional profile and prevalence of anemia among rural girls and boys. J Exer Sci Physiother. 2011;7(1):11-8.

20. Dixit S. A community based study on prevalence of anaemia among adolescent girls and its association with iron intake and their correlates. Indian J Prev Soc Med. 2011;42(4):393-8.

21. Panat AV. Iron deficiency among rural college girls: a result of poor nutrition and prolonged menstruation. JCNH. 2013;2(2):56-60.

22. Chaturvedi D, Chaudhuri PK, Priyanka, Chaudhary AK. Study of correlation between dietary habits and anemia among adolescence girls in Ranchi and its surronding area. Int $J$ Contemp Pediatr. 2017;4:1165-8.

How to cite: Ramya N, Shankar SP, Arvind J. A study of magnitude of anemia and its association with diet pattern in young females. Panacea J Med Sci. 2020;10(1):43-6. 